\title{
Coastal quality policies, ICZM implementation and adaptation to change: lessons learnt from the case study of Oléron Island, France
}

\author{
Virginie DUVAT, Department of Geography, University of la Rochelle-CNRS, \\ UMR LIENSs 6250, France \\ virginie.duvat@univ-Ir.fr
}

\begin{abstract}
:
The objective of this paper is to demonstrate that coastal quality policies can provide efficient support to the implementation of ICZM, and therefore, to the strengthening of the adaptive capacity of coastal territories to change. It is based on the lessons learnt from a case study conducted on the Atlantic coast of France. As they are holistic and systemic, coastal quality policies enable the integration of all challenges and stakeholders in territorial projects, and therefore are favourable to the identification and reduction of conflicts and inequalities, which in turn strengthen the societal cohesion required to cope with change. Thus, this article deals with two key issues: the barriers to management and adaptation, and the roles and responsibilities of stakeholders; showing that we don't necessarily have to renew our approaches, tools and practices, to adapt to change, and more particularly to global change.
\end{abstract}

Keywords: coastal quality, ICZM, adaptive capacity, global change, France

\section{Introduction}

Over the past twenty years, scientific works have demonstrated the value of beach quality policies based upon assessment procedures to support the implementation of sustainable development principles in tourism areas (De Ruyck et al., 1995; Cendrero et Fischer, 1997; Morgan, 1999; Cendrero et al., 2003; Ergin et al., 2006; Cervantes and Espejel, 2008). Most studies have highlighted the major importance of taking into account the views and experience of practitioners as well as user preferences in the development of assessment methodologies, notably regarding the choice of relevant criteria for defining and evaluating coastal quality. These studies have led to the establishment of practical and efficient tools such as checklists and databases to monitor change in coastal areas. The global and systemic approach developed in coastal quality policies and the effective integration of all of the stakeholders in the decision-making process have made such policies essential for putting Integrated Coastal Zone Management (ICZM) into practice.

France's delay in its ICZM implementation (Billé, 2004; Ferec-Meur, 2009) has served to highlight one of the current challenges faced today in this field, which is the identification of policies that have a potential for ICZM. We will show here that quality-based policies can provide a valuable opportunity for ICZM implementation (1). We will also explain the relevance of the "territorial project" concept for the success of ICZM initiatives, demonstrating the way in which it can remove barriers to management (2). Finally, we discuss how ICZM is a relevant management model for strengthening the adaptive capacity of coastal societies towards change, which will enable us to assess the merit of the renewal of our approaches, tools and methods in order to address the challenges of global change (3). 


\section{Coastal quality policies to assist ICZM implementation}

We first examine the theoretical foundations of our deliberation, and then discuss the way in which quality-based policies can support ICZM implementation.

\subsection{Theoretical foundations of deliberation}

B. Cicin-Sain (1993) and TE Chua (1993) remind us that ICZM is a continuous and dynamic process of coastal resource management, based on a holistic and integrative approach that responds to current issues and problems through the implementation of: (1) fundamental principles, such as those of integration, equity and participation; (2) a coherent strategy of territorial planning; and (3) specific accompanying methods based, in particular, on databases, GIS and status and monitoring indicators.

From a theoretical standpoint, three arguments can be used to support the idea that a coastal quality policy can be beneficial for ICZM implementation. The first is linked to the fact that this type of policy is based on a holistic and integrative approach. If we define coastal quality as "the elements that contribute to its value", it appears that quality relates as much to the environment and the economy as to socio-cultural aspects. It is therefore both "objective", since it can be measured by reference to established standards and conditions (water and environment quality, etc.), and "subjective" in that it relates to population categories that express specific preferences and expectations, especially in terms of quality of life, quality of tourism experience or landscape quality (Zube and Pitt, 1981; Pereira et al., 2003). The concept of quality, firstly because it covers a very broad field, therefore encourages integration, not only administrative and institutional, and at different scales, but also sectoral and spatial, and temporal since, like ICZM, quality improvement is a slow process. A quality-based policy also addresses the principle of public participation that is required by ICZM, primarily by user consultation through surveys (Morgan, 1999; Ergin et al., 2006), the realisation of public information awareness campaigns, and the implementation of development operations that meet user demand (Chua, 1993). Finally, quality policies are conducive to the integration of science and management because research can usefully contribute towards the building of a comprehensive view of coastal issues (Cicin-Sain, 1993), a common knowledge and to methods for the assessment and monitoring of environment quality and public policies (Cendrero and Fischer 1997; Cendrero et al., 2003).

Secondly, quality policies can support ICZM implementation because they are useful for the establishment of development and management plans at a territorial scale of suitable dimension (inter-municipality or regional), on the basis of shared issues (Cendrero and Fischer, 1997; Ferrarini et al., 2001). By strengthening territorial attractiveness (Leatherman, 1997) and reducing socio-spatial inequalities (Nelson and Botterill, 2002), quality policies can play a structural role for territories that are divided into multiple administrative jurisdictions and regulatory areas.

Finally, through the positive vision that it provides, a quality policy is able to renew the approach angle of a coastal public policy. By avoiding the stigmatisation of economic development, which often occurs with conservation policies, the quality approach leaves room for the construction of a real social project involving all stakeholders, which is a prerequisite for successful ICZM projects in an oft-confrontational context. 


\subsection{Example of the Oléron Coastal Quality Action Plan (OCQAP)}

The Oléron Coastal Quality Action Plan (OCQAP) is one of four action plans adopted by the Marennes Oléron District1 (MOD) in 2005 to implement its territorial project on the basis of a participatory approach. In 2004 this led to the adoption of a Charter for Sustainable Development. The charter defines the strategic priorities for the MOD's development: (1) The assertion of its territorial identity, in a context of strong tourism competition between neighbouring areas; (2) Making the territory more dynamic, since it is affected by the rural exodus and the marine cultural crisis, through the development of economic activities throughout the year; (3) The preservation of landscape quality and of the balance between heritage value, economic activities and urbanisation. To achieve these objectives, the charter outlines the following actions: (1) Networking of stakeholders, projects and resources; (2) The development of knowledge as a basis for decision making; (3) The experimental implementation of innovative ideas and methods aiming at making MOD a centre of excellence for sustainable development. In 2005, the MOD was one of the winning candidates in a national call for projects aiming to support the implementation of ICZM through a bottom-up process, which allowed it benefit from state support for two years. This first phase focused on ICZM appropriation and consisted in dissemination of the concept to stakeholders, obtaining their opinions regarding the priority of issues, designing tools for knowledge sharing (bibliographic database, issue monitoring chart, early indicators of sustainable development) and implementing new working methods (creation of monitoring and steering committees).

In this context, in 2008 the Oléron Island District Planning Community established OCQAP, the first concrete ICZM project. Through the redevelopment of beaches it aims to improve the quality of the coastal environment and tourist reception. It is based on recommendations for environmentally friendly development (materials of high quality environmental standard, removal of permanent buildings in the public maritime domain) and includes the restoration of sites degraded by coastal erosion and pollution. It also provides for the implementation of signage and public communication plans. It is based on a Charter for Beach Development and Protection, which was submitted to the Sites Commission2 and adopted by all the stakeholders involved in OCQAP. This Charter defines the overall strategy for beach development and the specific provisions that apply to the four types identified by the stakeholders (Fig. 1).

The development of OCQAP has followed the main stages involved in the establishment of an ICZM project (Fig. 2). It was based on a beach analysis that enabled the identification of problems and their causes. Subsequently, the involved parties assembled in a managerial committee and collectively developed and adopted this plan, as well as the Charter for Beach Development and Protection. A monitoring committee evaluates the realisation of this plan and seeks solutions to obstacles to its implementation.

1.The MOD is composed of two district planning communities, the Marennes Basin being one, which is located on the mainland, while the other is Oléron Island, which includes eight municipalities. The OCQAP concerns only Oléron Island. 


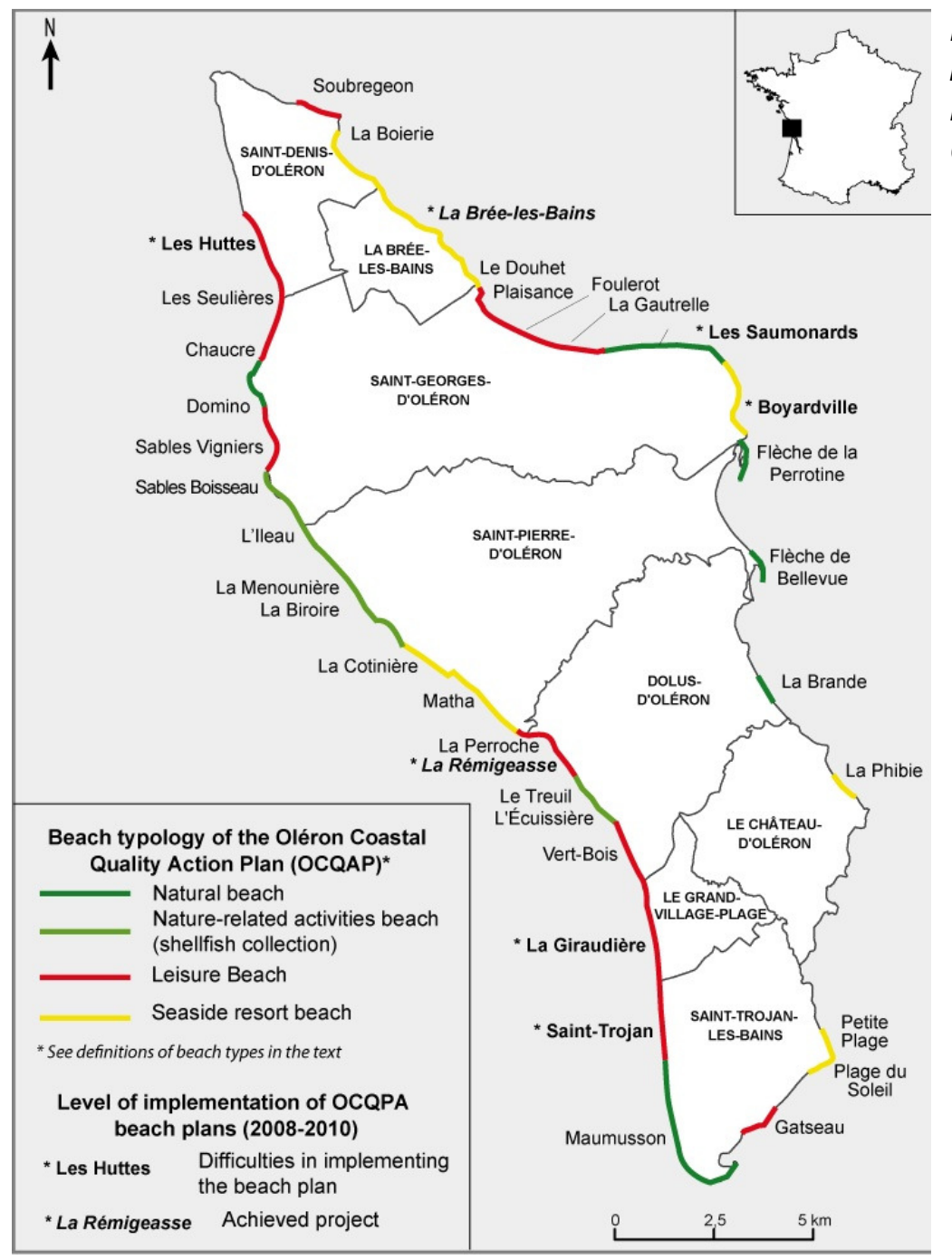

Fig.1 - Location of the beaches of Oléron Island and level of implementation of the OCQAP in 2010.

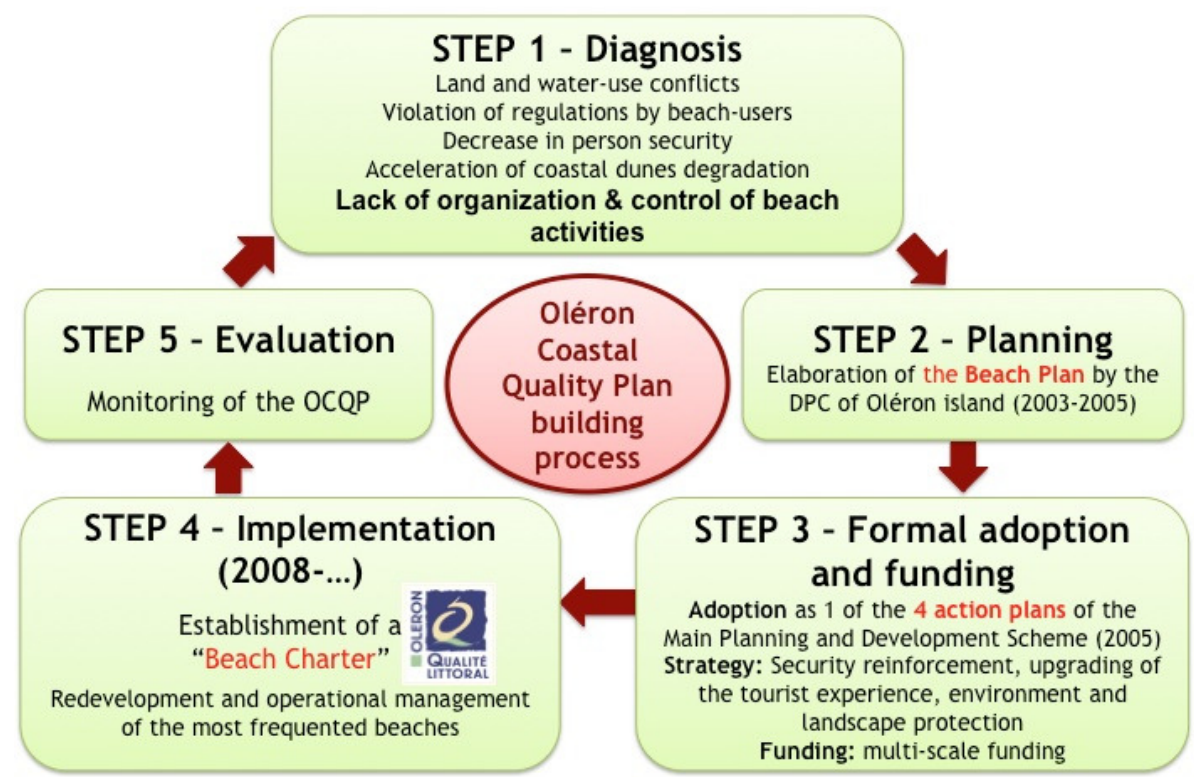

Fig.2 - Setting up of the OCQAP following the classical ICZM process

DCP: District Planning Community of Oléron Island (gathering the eight municipalities) 
In accordance to the wishes of stakeholders, a research programme named QUALIPLAGES3 was established in 2008 for a duration of four years in order to deepen the initial analysis, evaluate and monitor beach quality on the basis of meaningful indicators and to accompany the realisation of OCQAP through the continuous generation of knowledge and the creation of tools to assist the decision-making process, the most significant of which is a guide for the beaches (Duvat, 2010; Duvat, in press; Duvat and Mossot, in press). The programme is located at the interface between management and society, allowing it to contribute to a strengthening of the integration process and to consolidate stakeholder management capacities.

\section{From a territorial project to a "territory for projects": how ICZM policies can enhance the capacity of territories to deal with change}

We will see that the development of a territorial project enables a reduction in the number of obstacles to the implementation of public policies and thus strengthens a society's capacity to adapt to change.

\subsection{The territorial project, a relevant tool for building a coherent territory}

The participatory process launched in 2000 by the MOD (the "Public voice: action for sustainable and cohesive development" project) gave rise within five years to a coherent territorial project based on a shared vision of the future. This process was the origin of the formation of the Sustainable Development Charter and the Main Development and Planning Scheme, which are its main tools for territorial strategy and planning. The participatory nature of the approach has helped to integrate all interests, perspectives and challenges, and therefore to develop a project that is simultaneously comprehensive, coherent, fair and open to the future.

Since it is based on the identification of shared issues, the MOD's territorial project enabled the emergence of a coherent spatial entity in environmental, human, administrative and political terms. The spatial scale at which territorial issues are defined is relevant to translate policies into operational action plans and to reduce obstacles to their implementation. The issues constitute a relevant basis for the identification of involved parties and the appointment of an administrator of the action plans, and to determine the role of stakeholders in their implementation. In this case, OCQAP is the instrument that enables the realisation of the MOD territory project on Oléron Island. This action plan does not include the mainland region of the MOD, which has few sandy coasts and therefore does not share the same challenges as the island regarding beach quality. The designation of "a territory of issues" has allowed the easy identification of the project's administrator, namely the District Planning Community, which occupies a strategic position between the lower hierarchical levels (municipalities) and the higher ones (region, department, state). "Governing through the issues" thus enables the application of public policies at an adapted spatial scale, based on a legitimate and operational stakeholder, which creates a favourable context for their implementation. At Oléron, OCQAP efficiency is demonstrated by the strong and continuous mobilisation of political and administrative authorities and associations that participate in the conduction and realisation of OCQAP.

\footnotetext{
3. The research programme QUALIPLAGES (QUALIBEACH in English) is being coordinated by the author.
} 
This construction process can be conducive to the emergence of a "territory for projects" in the sense that the adopted methods and the experience gained facilitate the development of other projects. At Oléron, the Comprehensive Transportation Plan provides a good illustration of this phenomenon; it was launched in 2010 through the application of the same implementation process as for OCQAP, on the basis of a strong integration with the latter. The main challenges are therefore to identify good projects (in this instance, a project focusing on quality) and to implement these projects at an appropriate territorial scale with the support of a legitimate and operational project holder.

\subsection{From the "territory for projects" to management capacity: how integration can remove obstacles to the achievement of public policy}

The ICZM approach adopted at Oléron is beneficial for solving problems that impede the realisation of OCQAP. Despite the strong mobilisation of stakeholders, the main beach redevelopment projects have not been successful to date because of two obstacle types: stakeholder conflicts and financial difficulties.

Coastal management is complicated by the multiplicity of stakeholders, the complexity of administrative divisions and the recent multiplication of regulatory constraints (1986 French Coastal Act and protection statutes). This situation fosters conflicts of interest and usage, the resolution of which is made harder by the fact that such conflicts are centred on important issues, both economical and environmental. One ICZM objective is to achieve, through the implementation of the integration process, a reduction in the number of these conflicts by developing a shared vision of the coast. However, even when coherent and dynamic territorial projects emerge, some conflicts still arise. While the Charter for Beach Development and Protection4 envisages "little or no facilities" on "nature" beaches and "limited facilities" on "leisure" beaches, a "nature" beach such as Gatseau has many facilities and on a "leisure" beach such as les Huttes the facilities located on the dune (bar, toilet...) are challenged under the Coastal Act. Thus, although the Charter constitutes a common reference, it faces limitations in its application. This situation leads to conflicts that are blocking some redevelopment projects on the beaches of les Huttes and Saumonard (Fig.1), which could discourage mayors. The dynamic of progress and conflict resolution that is generated by the District Planning Community of Oléron ensures that their interest in OCQAP is maintained despite any difficulties.

The stakeholders also face the high realisation costs of certain redevelopment projects, a problem that is exacerbated by the reduction of public spending. In natural areas, the National Forestry Board (NFB), which manages dune ridges, is responsible for the design of redevelopment projects. It establishes very ambitious projects that do not always take into consideration the financial capabilities of stakeholders, especially municipalities that contribute up to 30 to $40 \%$ of a project's realisation cost. This difficulty is aggravated on sites that require large-scale environmental remediation operations, such as Saint-Trojan-les-

\footnotetext{
4. "Nature" beaches are defined as having a very strong natural characteristic that requires conservation and access limitation, they should therefore have little or no development. "Leisure" beaches are very popular, relatively remote from urban centres and accommodate any customer type. They should only have a limited amount of development. "Nature-related activities" beaches are typically sites for coastal foraging that do not necessarily require access limitation and for which only small developments are planned. "Seaside resort" beaches are close to urban centres, well equipped and targeted towards families in particular.
} 
Bains (landfills, ammunition reserves and World War II remnants - Fig.1). On this site, the redevelopment project was stopped for almost two years by the inability of stakeholders to finance it. This situation was recently unblocked by the downgrading of the redevelopment plan and the decision to carry out environmental remediation firstly only in the white dune. The exchange framework and the working methods implemented within OCQAP have played a major role in the identification and adoption of a solution of compromise that was acceptable to all.

\section{Should we renew our approaches, methods and tools to strengthen our adaptation capacity?}

One of the questions posed in the context of global change is whether it is necessary to renew our approaches, methods and tools to achieve the development and implementation of adaptation strategies. This equates to questioning ourselves on whether the evolution of issues and difficulties associated with coastal territorial management requires a change in management methods. To consider innovation as a prerequisite for adaptation is to call into doubt the management method that is ICZM. Here, we will provide an initial answer to this question based on the results of the OCQAP monitoring process made within the framework of the QUALIPLAGES programme.

Monitoring and evaluation of specific projects such as OQCAP show that the ICZM process is relevant to identify and solve problems in the sense that it enables stakeholders who share a common vision to be mobilised for negotiation purposes, a necessary step to remove obstacles preventing the realisation of public policy. The ICZM approach enables the continuous integration of new challenges, new problems and new stakeholders, which creates a favourable context for the implementation of concessionary solutions, although they can be difficult to identify and then apply. In this way it can help with adaptation to change. Three factors that are favourable to the implementation of adaptation strategies are: the inclusion of all involved parties, the evaluation process that accompanies any ICZM policy, and the recursive nature of this management mode. Indeed, by continually carrying out analyses, ICZM should help to identify the problems and issues related to global change. The collective development of strategies and plans for adaptation can also be supported by the ICZM process, which gives great importance to planning in territorial management. This is important because adaptation requires the implementation of strategies that rely at least in part on planning. Finally, the evaluation of public policies, which is part of the ICZM process, enables the definition of strengths and weaknesses of the management system, and to readjust, where appropriate, the adopted strategy. Therefore, ICZM is indeed relevant to the development and implementation of strategies to adapt to change because it is a process of continuous management of the territory resources system, and because it is effective for strengthening stakeholder capacity to manage this system.

\section{Conclusion}

The analysis of the relationship between ICZM, coastal quality policies and adaptation to global changes has firstly demonstrated that quality policies are conducive to ICZM implementation, which France has been slow to instigate, even though it constitutes an essential step in development of coastal territories. This analysis has enabled an emphasis to be placed on the need to define coherent territories on the basis of common issues in order to build a shared vision of the future. The development of long-term projects is 
structural, because it enables the identification of sustainable development trajectories, the implementation of which is based on territorial planning tools and on clearly identified stakeholders with clearly defined roles. A territory that has a strong administrative and policy coherence, and a strong societal cohesion, has an enhanced ability to manage changes and to develop adaptation strategies. The ICZM process enables the integration of changes as and when they occur and to adjust ongoing policies and projects from an adaptation perspective.

\section{References}

Billé, R., 2004. Gestion intégrée des zones côtières: quatre illusions bien ancrées, VertigO. 7 (3), published online on 8th September 2006. URL: http://vertigo.revues.org/1555.

Cendrero A., Fischer D.W., 1997, A procedure for assessing the environmental quality of coastal areas for planning and management. Journal of Coastal Research, 13(3): 732-744.

Cendrero A., Francés E., Del Corral D., Ferman J.L., Fischer D., Del Rio L., Camino M., Lopez A., 2003, Indicators and indices of environmental quality for sustainability assessment in coastal areas. Application to case studies in Europe and the Americas. Journal of Coastal Research, 19(4): 919933.

Cervantes O., Espejel I., 2008, Design of an integrated evaluation index for recreational beaches. Ocean and Coastal Management, 51: 410-419.

Chua T-E, 1993. Essential elements of Integrated Coastal Zone Management. Ocean and Coastal Management, 21: 81-108.

Cicin-Sain, B., 1993. Sustainable development and integrated coastal management. Ocean and Coastal Management, 21: 11-43.

De Ruyck A.M.C., Soares A.G., McLachlan A., 1995, Factors influencing beach choice on three South African beaches: a multivariate analysis. Geojournal, 36(4): 345-352.

Duvat, V., 2010. Beach quality assessment as a tool for promoting sustainability in tourist islands: the case study of Oléron Island, France. Fourth International Conference on Sustainable Tourism, New Forest, UK, 5-7/07/10, WIT Press, 99-111.

Duvat, V., à paraître. La qualité des plages au cœur de la Gestion Intégrée des Zones Côtières: l'exemple du plan d'action Oléron Qualité Littoral. Vertigo, $25 \mathrm{p}$.

Duvat., V., Mossot, G., in press. Guide des plages de l'île d'Oléron, LIENSs publication.

Ergin A., Williams A.T., Micallef A., 2006, Coastal scenery: appreciation and evaluation. Journal of Coastal Research, 22(4) : 958-964.

Ferrarini A., Bodini A., Becchi M., 2001, Environmental quality and sustainability in the province of Reggio Emilia (Italy): using multi-criteria analysis to assess and compare municipal performance. Journal of Environmental Management, 63: 117-131.

Meur-Férec, C., 2009. La GIZC à l'épreuve du terrain: premiers enseignements d'une expérience française. VertigO. URL: http://vertigo.revues.org/8331.

Morgan R., 1999, A novel, user-based rating system for tourist beaches. Tourism Management, 20: 393-410.

Nelson C., Botterill D., 2002, Evaluating the contribution of beach quality awards to the local tourism industry in Wales -The Green Coast Award. Ocean and Coastal Management, 45: 157-170.

Pereira L.C.C., Jiménez J.A., Medeiros C., DaCosta R. M., 2003, The influence of the environmental status of Casa Caiada and Rio Doce beaches (NE Brazil) on beach users. Ocean and Coastal Management, 46: 1011-1030.

Zube E.H., Pitt D.G., 1981, Cross-cultural perceptions of scenic and heritage landscapes. Landscape Planning, 8: 69-87.

\section{Acknowledgements}

The author gratefully acknowledges the Région Poitou-Charentes and the District Community Planning of Oléron Island for financing the QUALIPLAGES research programme. 